\title{
RELATIONSHIP MARKETING DAN CROSS SELLING TERHADAP KINERJA PEMASARAN PADA PT. ASURANSI UMUM VIDEI KANTOR PEMASARAN JAMBI
}

\author{
Apris $^{1)}$, Dahmiri $^{2)^{*}}$ \\ ${ }^{1)}$ Karyawan PT. Asuransi Umum Videi KP Jambi \\ ${ }^{2)}$ Prodi Manajemen FEB Universitas Jambi \\ *Corresponding author : dahmiri@unja.ac.id
}

\begin{abstract}
Abstrak.
Penelitian ini bertujuan untuk menganalisis pengaruh Relationship Marketing dan Cross Selling terhadap Kinerja Pemasaran pada PT. Asuransi Umum Videi Kantor Pemasaran Jambi. Dalam penelitian ini pendekatan yang digunakan adalah deskriptif kuantitatif. Sampel diambil sebanyak 90 orang pelanggan atau nasabah PT. Asuransi Umum Videi Kantor Pemasaran Jambi. Data yang digunakan dalam penelitian ini adalah data primer berupa kuesioner. Berdasarkan analisis data, maka kesimpulan yang dapat diambil dari penelitian ini adalah terdapat pengaruh Relationship Marketing terhadap Kinerja Pemasaran pada PT. Asuransi Umum Videi Kantor Pemasaran Jambi. Terdapat pengaruh Cross Selling terhadap Kinerja Pemasaran pada PT. Asuransi Umum Videi Kantor Pemasaran Jambi. Terdapat pengaruh Relationship Marketing dan Cross Selling secara simultan terhadap Kinerja Pemasaran pada PT. Asuransi Umum Videi Kantor Pemasaran Jambi.
\end{abstract}

Kata Kunci : Kinerja Pemasaran, Relationship Marketing dan Cross Selling

\begin{abstract}
Abstrack.
This study aims to analyze the effect of Relationship Marketing and Cross Selling on Marketing Performance at PT. Videi General Insurance Jambi Branch. In this research, the approach used is descriptive quantitative. Samples were taken as many as 90 customers or customers of PT. Videi General Insurance Jambi Marketing Office. The data used in this study are primary data in the form of a questionnaire. Based on data analysis, the conclusion that can be drawn from this study is that there is an effect of Relationship Marketing on Marketing Performance at PT. Videi General Insurance Jambi Marketing Office. There is an influence of Cross Selling on Marketing Performance at PT. Videi General Insurance Jambi Marketing Office. There is a simultaneous influence of Relationship Marketing and Cross Selling on Marketing Performance at PT. Videi General Insurance Jambi Marketing Office.
\end{abstract}

Keywords: Marketing Performance, Relationship Marketing and Cross Selling

\section{PENDAHULUAN}

Dalam bisnis khususnya di bidang industri asuransi baik Badan Usaha Milik Negara (BUMN) maupun swasta di Indonesia yang turut serta berkompetisi dalam memberikan perlindungan kepada masyarakat dan ikut berpartisipasi dalam kemajuan perekonomian Negara Republik Indonesia. Di era teknologi modern seperti sekarang ini membuat banyak kesadaran masyarakat yang bertambah akan pentingnya berasuransi. Dalam membuat keputusan untuk menentukan suatu perlindungan dimasa depan baik perlindungan kesehatan, harta benda dan lain sebagainya, ini merupakan salah satu faktor berkembangnya industri perasuransian di Indonesia yang juga bagian dalam perkembangan ekonomi di Indonesia. 
Relationship marketing adalah cara usaha pemasaran pada pelanggan yang meningkatkan pertumbuhan jangka panjang perusahaan dan kepuasan maksimum pelanggan. Pelanggan yang baik merupakan suatu asset di mana bila ditangani dan dilayani dengan baik akan memberikan pendapatan dan pertumbuhan jangka panjang bagi suatu perusahaan (Kotler dan Armstrong, 2010). Dalam rangka menciptakan nilai, mempertahankan nasabah dan mendorong pembelian ulang dengan produk tambahan, relationship marketing berkembang di seluruh area perusahaan. hubungan baik (dalam system marketing : silatuhrahmi) dengan segalah stakeholder melalui realationship marketing dieksekusi untuk menciptakan nilai bagi nasabah (pelanggan) di semua operasi perusahaan untuk merespon permintaan nasabah dan penyediaanya disesuaikan dengan pengalaman nasaba secara interaktif untuk mengakuisisi dan mempertahankan hubungan jangka panjang dengan pelanggan, mengeksplorasi biaya layanan agar lebih efisien dan menawarkan kualitas layanan dengan selalu ada waktu kapan pun nasabah membutuhkan di harapkan dapatselalu lebih baik dari pada competitor. Dengan kemampuan PT. Asuransi Umum Videi Kantor Pemasraan Jambi mencoba untuk memadukan pemasaran opensif eksternal, pemasaran defensif internal dan pemasaran interaktif menjadi kekuatan relationship marketing dalam mengikat hubungan nasabah dengan perusahaan.

PT. Asuransi Umum Videi Kantor Pemasaran Jambi dari penjualan produk-produk surety bond : jaminan penawaran (Bid Bond), Jaminan pelaksanaan (performance Bond) Jaminan Uang Muka (Advance Paimet Bond) dan jaminan pemeliharan (Maintenance Bond) juga di harapkan agar proyek proyek yang bisa di cover dengan asuransi CAR (Construction All Risks) dan EAR (Erection All Risks) Insurance, Baik CAR dan EAR yang memberikan ganti rugi akibat terjadinya risiko yang dapat dinilai pada saat terjadinya kerugian karena suatu peristiwa tak terduga dan terjadinya tiba-tiba dan nasabah tersebut juga mengasuransikan kendaraan, gedung kantor, rumah dan karyawan dengan asuransi kecelakaan diri dan berbagai produk asuransi lainya.

Menurut Chasin (2003) cross selling adalah strategi perusahaan untuk meningkatkan penjualan produk baru kepada konsumen yang sudah ada, berdasarkan pengalaman masa lalu mereka dalam mengkonsumsi produk perusahaan tersebut sebelumnya. Cross selling di design untuk meningkatkan kepercayaan konsumen, dan mengurangi kemungkinan berpindahnya konsumen ke perusahaan lain (Mempertahankan Pelanggan). Metode cross selling dengan menawarkan dan menjual produk tambahan seperti produk asuransi kebakaran gedung, kantor, rumah tinggal produk asuransi kendaraan yang di harapkan dapat meningkatkan pertumbuhan premi perusahaan dan menjaga agar perusahaan tetap eksis dan meningkatnya kinerja pemasaran.

Penerapan cross selling dapat meningkatkan jumlah transaksi penjualan serta memperluas segmentasi pelanggan dan area penjualan. Hal ini didukung oleh teori kinerja pemasaran merupakan ukuran prestasi yang diperoleh dari proses aktivitas pemasaran secara menyeluruh dari sebuah organisasi artinya, apabila cross selling meningkat kinerja penjualan akan meningkat. Untuk meningkatkan kinerja pemasaran maka di perlukan cross selling yang efektif.

Dalam jurnal Fathoni (2019) penerapan Cross Selling dapat meningkatkan jumlah transaksi penjualan serta memperluas segmentasi pelanggan dan area penjualan. Hal ini didukung oleh teori kinerja pemasaran merupakan ukuran prestasi yang diperoleh dari proses aktivitas pemasaran secara menyeluruh dari sebuah organisasi (Ratnawati, 2013). Adapun kinerja pemasaran seperti disebutkan oleh Ferdinand T, (2000) menyatakan bahwa kinerja pemasaran merupakan faktor yang seringkali digunakan untuk mengukur dampak dari strategi yang diterapkan perusahaan. Selanjutnya Ferdinand juga menyatakan 
bahwa kinerja pemasaran yang baik dinyatakan dalam tiga besaran utama nilai, yaitu nilai penjualan, pertumbuhan penjualan, dan porsi pasar. Kinerja pemasaran merupakan ukuran prestasi yang diperoleh dari aktivitas proses pemasaran secara menyeluruh dari sebuah perusahaan atau organisasi.

Dari data penjualan polis PT. Asuransi Umum Videi Kantor Pemasaran Jambi pada tahun 2016-2020 mengalami peningkatan dan penurunan. Penurunan yang signifikan terjadi pada tahun 2020 disebabkan oleh munculnya persaingan baru dan meningkatnya kualitas dari kompetitor yang lama, yang juga di untungkan oleh polemik yang muncul di tahun 2016 tersebut. Dengan munculnya pesaing baru dan kompetitor yang semakin handal berarti konsumen mempunyai pilihan yang lebih banyak baik dalam kualitas, harga, produk dan sebagainya. Industri asuransi ikut menjadi dampak pandemi corona COVID-19. Kondisi itu setidaknya tercermin dari laporan Otoritas Jasa Keuangan (OJK) yang mencatat perolehan premi asuransi per Maret 2020 yang tumbuh lambat. Rendahnya penerimaan premi membuat industri asuransi jadi pusing tujuh keliling akibatnya, kinerja keuangan industri asuransi pun ikut goyang.

Dengan relationship marketing dan cross selling ini sangat diharapkan agar dapat membawa perusahan ke arah yang lebih baik lagi demi mencapai kinerja pemasaran yang secara otomatis akan dapat meningkatkan pertumbuhan produksi dari berbagai macam produk yang ada secara menyeluruh agar prusahaan tetap berkembang dan menjadi salah satu perusahaan asuransi nasional yang menjadi bagian dari pertumbuhan ekonomi dan pembukaan lapangan pekerjaan untuk membawa kesejahteraan bagi karyawan dan bermanfaat bagi masyarakat luas.

Tujuan dari penelitian ini adalah untuk menjelaskaan pengaruh Relationship Marketing dan Cross Selling terhadap Kinerja Pemasaran PT. Asuransi Umum Videi Kantor Pemasaran Jambi.

Rundengan (2019) menjelaskan adanya hubungan yang positif antara relationship marketing dan kinerja pemasaran. Hal tersebut dapat diartikan bahwa semakin baik relationship marketing, maka akan meningkatkan kinerja pemasaran. Dalam jurnal mitra manajemen, Menurut Palmatier (2008) relationship marketing adalah proses mengidentifikasi, mengembangkan, memelihara dan hubungan pertukaran relasional yang bertujuan untuk meningkatkan kinerja. Penelitian yang dilakukan Palmatier (2008) berkaitan dengan relasi bisnis menunjukkan bahwa membangun hubungan yang kuat dalam bisnis lebih efektif dalam meningkatkan kinerja perusahaan dibandingkan dengan hubungan bisnis dengan pasar konsumen langsung.

Palmatier (2008), ketergantungan diantara mitra antar perusahaan bukanlah kaitan langsung dari kinerja relationship melainkan memberikan latar belakang kontekstual yang dengannya hubungan dapat berkembang, sedangkan kepercayaan, komitmen, dan investasi hubungan secara langsung meningkatkan hubungan antar perusahaan dan kinerja keuangan. Dengan demikian, serupa dengan temuan meta-analisis mediator relasional, penelitian ini menunjukkan bahwa kepercayaan dan komitmen tidak sepenuhnya memediasi dampak investasi hubungan terhadap hasil kinerja.

$\mathrm{H}_{1}$ : Relationship marketing berpengaruh signifikan terhadap kinerja pemasaran

Fathoni (2019) Menjelasakan bahwa penerapan Cross Selling dapat meningkatkan jumlah transaksi penjualan serta memperluas segmentasi pelanggan dan area penjualan. Hal ini didukung oleh teori kinerja pemasaran merupakan ukuran prestasi yang diperoleh dari proses aktivitas pemasaran secara menyeluruh dari sebuah organisasi merupakan faktor yang seringkali digunakan untuk mengukur dampak dari strategi yang diterapkan 
perusahaan Yudith, (2005). Selanjutnya Ferdinand juga menyatakan bahwa kinerja pemasaran yang baik dinyatakan dalam tiga besaran utama nilai, yaitu nilai penjualan, pertumbuhan penjualan, dan porsi pasar. Kinerja pemasaran merupakan ukuran prestasi yang diperoleh dari aktifitas proses pemasaran secara menyeluruh dari sebuah perusahaan atau organisasi Ferdinand (2000) .

Rundengan (2019) Cross selling dan kinerja Pemasaran berpengaruh negatif (tidak searah) sehingga dapat dikatakan bahwa semakin tinggi cross selling maka akan semakin rendah kinerja Pemasaran. Hasil ini tidak sesuai dengan teori yang menyatakan adanya hubungan positif antara cross selling dengan kinerja penjualan. Artinya, apabila cross selling meningkat kinerja penjualan akan menurun. Untuk meningkatkan kinerja pemasaran maka di perlukan pengurangan cross selling.

$\mathrm{H}_{2}$ : Cross Selling berpengaruh signifikan terhadap kinerja pemasaran

Dengan relationship marketing dan cross selling ini sangat di harapkan agar dapat membawa perusahan ke arah yang lebih baik lagi demi mencapai kinerja pemasaran yang secara otomatis akan dapat meningkatkan pertumbuhan produksi dari berbagai macam produk yang ada secara menyeluruh agar perusahaan tetap berkembang dan menjadi salah satu perusahaan asuransi nasional yang menjadi bagian dari pertumbuhan ekonomi dan pembukaan lapangan pekerjaan untuk membawa kesejahteraan bagi karyawan dan bermanfaat bagi masyarakat luas.

Rundengan (2019), Mengatakan bahwa Relationship Marketing, dan Cross Selling secara simultan berpengaruh signifikan terhadap peningkatan Kinerja Pemasaran. Terdapat hubungan yang kuat antara relationship marketing dan cross selling terhadap kinerja pemasaran.

$\mathrm{H}_{3}$ : Relationship marketing dan cross selling secara simultan berpengaruh signifikan terhadap kinerja pemasaran

\section{METODE PENELITIAN}

Dalam penelitian ini pendekatan yang digunakan adalah deskriptif dan verifikatif dengan penelitian studi empiris. Adapun tujuannya untuk menjelaskan bagaimana hubungan dan pengaruh suatu variabel terhadap variabel lainnya. Metode penelitian verifikatif digunakan untuk menjawab rumusan masalah mengenai pengaruh Relationship marketing terhadap kinerja pemasaran PT. Asuransi umum Videi Kantor Pemasaran Jambi, Pengaruh Cross Selling Terhadap Kinerja Pemasaran PT. Asuransi Umum Videi Kantor Pemasaran Jambi dan Pengaruh Relationship Marketing dan Cross Selling terhadap Kinerja Pemasraan PT. Asuransi Umum Videi Kantor Pemasaran Jambi.

Data yang digunakan untuk menguji hipotesis penelitian ini merupakan data primer yang di peroleh secara langsung dari subjek penelitian dalam hal ini reponden dengan menggunakan kuesioner. Untuk menjawab dan mengungkap tujuan penelitian.

Pengolahan data dilakukan apabila data telah terkumpul, dilakukan dengan mempergunakan perangkat computer dan menggunakan program SPSS (Statistical Product and Service Solution) Selanjutnya teknik yang digunakan dalam membahas pengaruh Relationship Marketing dan cross selling terhadap Kinerja Pemasaran pada PT. Asuransi Uumum Videi Cabang Jambi.

\section{HASIL DAN PEMBAHASAN}

\section{Karakteristik Responden}

Responden dalam penelitian ini adalah nasabah PT. Asuransi Umum Videi Kantor Pemasaran Jambi. Penelitian ini bertujuan untuk mengetahui pengaruh Relationship 
Marketing dan Cross Selling terhadap Kinerja Pemasaran PT. Asuransi Umum Videi Kantor Pemasaran Jambi. Metode penarikan sampel yang digunakan adalah teknik simple random sampling atau pengambilan secara acak sederhana. Sampel dalam penelitian berjumlah 90 orang nasabah PT. Asuransi Umum Videi Kantor Pemasaran Jambi. Berikut ini karakteristik responden dalam penelitian yaitu berdasarkan jenis kelamin, usia, pendidikan dan lama bekerja.

Tabel 1. Karakteristik Responden

\begin{tabular}{lrr}
\hline \multicolumn{1}{c}{ Karakteristik Responden } & Jumlah (Orang) & Persentase (\%) \\
\hline Jenis Kelamin & 62 & 68.89 \\
Laki-Laki & 28 & 31.11 \\
Perempuan & & \\
Usia & 4 & 4.44 \\
< 20 Tahun & 29 & 32.22 \\
21-30 Tahun & 35 & 38.89 \\
31-40 Tahun & 22 & 24.44 \\
>1 Tahun & & \\
Pendidikan & 5 & 5.56 \\
SMA & 19 & 21.11 \\
D1-DIV & 42 & 46.67 \\
S1 & 24 & 26.67 \\
S2 & & \\
Pekerjaan & 9 & 10.00 \\
PNS & 13 & 14.44 \\
Pegawai BUMN & 33 & 36.67 \\
Pegawai Swasta & 18 & 20.00 \\
Wiraswasta & 5 & 5.56 \\
Pelajar/Mahasiswa & 12 & 13.33 \\
Lain-lain & & \\
\hline
\end{tabular}

Dari tabel diatas, dapat disimpulkan bahwa mayoritas responden berjenis kelamin laki-laki hal ini menunjukkan bahwa nasabah PT. Asuransi Umum Videi Kantor Pemasaran Jambi rata-rata berjenis kelamin laki-laki, hal ini disebabkan nasabah laki-laki mempunyai tugas mencari nafkah dan membutuhkan stamina yang kuat serta untuk memproteksi keluarga sehingga nasabah pria lebih banyak dibandingkan perempuan. Mayoritas responden berusia 31-40 tahun hal ini menunjukkan bahwa usia nasabah PT. Asuransi Umum Videi Kantor Pemasaran Jambi karena pada tingkat usia sekitar 31-40 tahun merupakan masa yang matang dan produktif serta berpengalaman dibidangnya sehingga diharapkan mampu mencari nafkah dengan baik guna peningkatan taraf ekonomi keluarga. Mayoritas responden berpendidikan S1 hal ini menunjukkan bahwa nasabah PT. Asuransi Umum Videi Kantor Pemasaran Jambi perusahaan memiliki pengetahuan lebih baik ketimbang DI-DIV atau SMA. mayoritas responden memiliki pekerjaan pegawai swasta hal ini menunjukkan bahwa nasabah PT. Asuransi Umum Videi Kantor Pemasaran Jambi yang mempunyai pekerjaan karyawan swasta tidak mendapatkan dana pensiun dan rawan terhadap Pemutusan Hubungan Kerja (PHK) sehingga untuk memproteksi dalam keluarga menggunakan PT. Asuransi Umum Videi Kantor Pemasaran Jambi. 


\section{Uji Validitas}

Instrumen yang valid berarti intrumen tersebut dapat digunakan untuk mengukur apa yang seharusnya diukur. Penelitian ini menggunakan pengukuran dengan melihat output Pearson Correlation. Dengan kriteria jika nilai $\mathrm{r}_{\text {hitung }}>\mathrm{r}_{\text {tabel }}$ maka pernyataan dalam kuesioner berkorelasi signifikan terhadap skor total (artinya item atau pernyataan dinyatakan valid). Pengujian menggunakan uji dua sisi dengan taraf signifikansi 0.05. Sesuai rumus yang akan kita digunakan yaitu $\mathrm{df}=\mathrm{n}-2,(90-2=88)$ maka didapat $\mathrm{r}_{\text {tabel }}$ sebesar $0,207$.

Dari 26 pernyataan yang diajukan kepada 90 responden ternyata variabel Relationship Marketing $\left(\mathrm{X}_{1}\right)$, Cross Selling $\left(\mathrm{X}_{2}\right)$ dan Kinerja Pemasaran (Y) tidak ada pernyataan yang tidak valid karena nilai $r_{\text {hitung }}>r_{\text {tabel }}$. Kesemua pernyataan yang valid membuktikan bahwa pernyataan yang diberikan kepada responden dapat direspon dan dimengerti dengan baik karena adanya keterkaitan pernyataan mengenai Relationship Marketing $\left(\mathrm{X}_{1}\right)$, Cross Selling $\left(\mathrm{X}_{2}\right)$ dan Kinerja Pemasaran (Y).

\section{Uji Reliabilitas}

Uji reliabilitas digunakan untuk mengetahui konsistensi alat ukur yang biasanya menggunakan kuesioner. Maksudnya apakah alat ukur tersebut akan mendapatkan pengukuran yang tetap konsisten jika pengukuran diulang kembali. Untuk menentukan apakah instrumen reliabel atau tidak menggunakan batasan Nilai Cronbach's Alpha sebesar $>0,6$.

Tabel 2. Hasil Uji Reliabilitas

\begin{tabular}{clccc}
\hline No & \multicolumn{1}{c}{ Variabel } & Nof item & Cronbach's Alpha & Ket \\
\hline 1 & Relationship Marketing $\left(\mathrm{X}_{1}\right)$ & 10 & 0,669 & Reliabel \\
2 & Cross Selling $\left(\mathrm{X}_{2}\right)$ & 8 & 0,759 & Reliabel \\
3 & Kinerja Pemasaran $(\mathrm{Y})$ & 8 & 0,691 & Reliabel \\
\hline
\end{tabular}

\section{Uji Normalitas}

Uji normalitas digunakan untuk mengetahui apakah nilai residual yang digunakan terdistribusi normal atau tidak. Untuk melakukan uji normalitas distribusi data, penulis menggunakan One Sample Kolmogorof Smirnov Test dari program SPSS. Normalitas distribusi data dihitung dengan cara membandingkan nilai Asymtotic Significance yang diperoleh dengan nilai $\alpha=0,05$. Apabila Asymp Sig $>\alpha=0,05$ maka data dinyatakan normal. Hasil uji normalitas menggunakan One Sample Kolmogorof Smirnov Test sebagai berikut :

Uji normalitas data sampel yang menggunakan rumus Kolmogrov-Smirnov menghasilkan besaran statistik dan taraf kepercayaannya (Significance Level) ditemukan $p$-value antara 0,142 sampai dengan 0,695 lebih besar dari taraf signifikan 0,05 ( $p$-value > 0.05) untuk semua variabel penelitian yaitu variabel Relationship Marketing $\left(\mathrm{X}_{1}\right)$, Cross Selling $\left(\mathrm{X}_{2}\right)$ dan Kinerja Pemasaran $(\mathrm{Y})$. Besaran signifikasi ( $p$-value > 0.05) ini menunjukkan bahwa data sampel berdistribusi normal.

Hasil uji normalitas dengan menggunakan grafik Normal P-P Plot of regression standardized residual memberikan pola distribusi yang melenceng ke kanan yang artinya adalah data berdistribusi normal. Selanjutnnya pada grafik Normal P-P Plot of regression standardized residual terlihat titik-titik mengikuti dan mendekati garis diagonalnya sehingga dapat disimpulkan bahwa model regresi memenuhi asumsi normalitas. 


\section{Analisis Regresi Linier Berganda}

Untuk menetapkan rumusan persamaan Regresi Linier Berganda (Multiple Linear Regression) pengaruh relationship marketing dan cross selling terhadap kinerja pemasaran pada PT. Asuransi Umum Videi Kantor Pemasaran Jambi perlu dilakukan analisis Regresi Linier berganda dengan menggunakan fasilitas program SPSS, dapat dilihat pada tabel dibawah ini :

Tabel 3. Hasil Regresi Linier Berganda

\begin{tabular}{|c|c|c|c|c|c|}
\hline \multirow[b]{2}{*}{ Model } & \multicolumn{2}{|c|}{$\begin{array}{l}\text { Unstandardized } \\
\text { Coefficients }\end{array}$} & \multirow{2}{*}{$\begin{array}{c}\text { Standardized } \\
\text { Coefficients } \\
\text { Beta }\end{array}$} & \multirow[b]{2}{*}{$\mathrm{t}$} & \multirow[b]{2}{*}{ Sig. } \\
\hline & B & $\begin{array}{l}\text { Std. } \\
\text { Error }\end{array}$ & & & \\
\hline $1 \quad$ (Constant) & 1.908 & 3.085 & & .619 & .538 \\
\hline Reliationship Marketing & .460 & .071 & .493 & 6.483 & .000 \\
\hline Cross Selling & .397 & .071 & .427 & 5.625 & .000 \\
\hline
\end{tabular}

Formula persamaan regresi linier berganda yaitu $Y=1,908+0,460 X_{1}+0,397 X_{2}+$ e. Pengaruh masing-masing variabel independen terhadap variabel dependen dapat dijelaskan sebagai berikut :

1. Nilai Konstanta (a) sebesar 1,908 menyatakan bahwa jika ada peningkatan variabel Relationship Marketing $\left(\mathrm{X}_{1}\right)$ dan Cross Selling $\left(\mathrm{X}_{2}\right)$ maka Kinerja Pemasaran (Y) mengalami sebesar 1,908.

2. Koefisien regresi variabel Relationship Marketing $\left(\mathrm{X}_{1}\right)$ sebesar 0,460 menunjukkan bahwa setiap perubahan atau peningkatan Relationship Marketing $\left(\mathrm{X}_{1}\right)$ sebesar 1 maka mengakibatkan peningkatan atau mempengaruhi Kinerja Pemasaran (Y) sebesar 46\%.

3. Koefisien regresi variabel Cross Selling $\left(\mathrm{X}_{2}\right)$ sebesar 0.397 menunjukkan bahwa setiap perubahan atau peningkatan Cross Selling $\left(\mathrm{X}_{2}\right)$ sebesar 1 maka mengakibatkan peningkatan atau mempengaruhi Kinerja Pemasaran (Y) sebesar 39,7\%.

\section{Analisis Koefisien Determinasi}

Analisis ini digunakan untuk mengambil seberapa jauh variabel bebas dapat menjelaskan variabel terikat, maka perlu diketahui nilai koefisien determinasi atau penentuan $R^{2}$ Nilai $R^{2}$ ini berkisar antara $0-1$, semakin mendekati 1 nilai $R^{2}$ tersebut berarti semakin besar variabel independen mampu menerangkan variabel dependen. Analisis terhadap nilai $R$-square $\left(\mathrm{R}^{2}\right)$ ini digunakan untuk mengetahui sejauh mana variabel bebas (X) dapat menerangkan hubungan perubahan variabel terikat (Y). Sifat-sifat $R$-square sangat dipengaruhi oleh banyak variabel bebas dimana semakin banyak variabel bebas semakin besar nilai $R$-square.

Tabel 4. Hasil Uji Koefisien Determinasi

\begin{tabular}{lcrrrr}
\hline Model & R & R Square & $\begin{array}{l}\text { Adjusted } \\
\text { R Square }\end{array}$ & $\begin{array}{l}\text { Std. Error of } \\
\text { the Estimate }\end{array}$ & $\begin{array}{l}\text { Durbin- } \\
\text { Watson }\end{array}$ \\
\hline 1 & $.726(a)$ & .527 & .516 & 2.954 & 1.849 \\
\hline
\end{tabular}

Berdasarkan tabel Model Summary di atas nilai koefisien determinasinya $R$ Square sebesar 0,527 (52,7\%). Variabel Relationship Marketing $\left(\mathrm{X}_{1}\right)$ dan Cross Selling $\left(\mathrm{X}_{2}\right)$ berpengaruh terhadap variabel Kinerja Pemasaran (Y) sedangkan sisanya sebesar 47,3\% berpengaruh dengan faktor lain yang tidak diteliti seperti kualitas pelayanan, promosi, komitmen organisasi dan lain-lain. 


\section{Uji t (Secara Parsial)}

Uji t dikenal dengan uji parsial, yaitu untuk menguji bagaimana pengaruh masingmasing variabel bebas secara sendiri-sendiri terhadap variabel terikat. Uji ini dilakukan dengan mambandingkan sig $\mathrm{t}$ dan $\alpha(0,05)$.

$\mathrm{t}_{\text {tabel }}=1,987(\mathrm{df}=\mathrm{n}-\mathrm{k}=90-2=88)$ ditaraf signifikan 0,05

Tabel 5. Hasil Uji t

\begin{tabular}{|c|c|c|c|c|c|}
\hline \multirow[b]{2}{*}{ Model } & \multicolumn{2}{|c|}{$\begin{array}{c}\text { Unstandardized } \\
\text { Coefficients }\end{array}$} & \multirow{2}{*}{$\begin{array}{c}\begin{array}{c}\text { Standardized } \\
\text { Coefficients }\end{array} \\
\text { Beta }\end{array}$} & \multirow[b]{2}{*}{$\mathrm{t}$} & \multirow[b]{2}{*}{ Sig. } \\
\hline & B & $\begin{array}{l}\text { Std. } \\
\text { Error }\end{array}$ & & & \\
\hline $1 \quad$ (Constant) & 1.908 & 3.085 & & .619 & .538 \\
\hline Reliationship Marketing & .460 & .071 & .493 & 6.483 & .000 \\
\hline Cross Selling & .397 & .071 & .427 & 5.625 & .000 \\
\hline
\end{tabular}

Berdasarkan data hasil uji statistik $\mathrm{t}$ pada tabel diatas, diperoleh nilai sig t variabel Relationship Marketing sebesar 0,000 $<\alpha=0,05$ dan $t_{\text {hitung }}>t_{\text {tabel }}(6,483>1,987)$, maka dapat dinyatakan bahwa $\mathrm{H}_{1}$ diterima dan $\mathrm{H}_{0}$ ditolak. Dengan demikian dapat dibuktikan bahwa hipotesis $\mathrm{H}_{1}$ yang dinyatakan dengan terdapat pengaruh Relationship Marketing terhadap Kinerja Pemasaran pada PT. Asuransi Umum Videi Kantor Pemasaran Jambi diterima.

Adanya pengaruh yang positif antara relationship marketing dan kinerja pemasaran. Hal tersebut dapat diartikan bahwa semakin baik relationship marketing, maka akan meningkatkan kinerja pemasaran. Dalam jurnal mitra manajemen, Menurut Palmatier (2008) relationship marketing adalah proses mengidentifikasi, mengembangkan, memelihara dan hubungan pertukaran relasional yang bertujuan untuk meningkatkan kinerja. Penelitian yang dilakukan Palmatier (2008) berkaitan dengan relasi bisnis menunjukkan bahwa membangun hubungan yang kuat dalam bisnis lebih efektif dalam meningkatkan kinerja perusahaan dibandingkan dengan hubungan bisnis dengan pasar konsumen langsung. Rundengan. (2019), Sunarti, V. S. (2018) dan Fradisa, M. A. \& Rochmah, T. N, (2013) menyatakan terdapat pengaruh yang signifikan antara variabel Relationship Marketing terhadap kinerja pemasaran.

Hasil uji statistik t pada tabel diatas, diperoleh nilai sig t variabel Cross Selling sebesar $0,000<\alpha=0,05$ dan $t_{\text {hitung }}>t_{\text {tabel }}(5,625>1,987)$, maka dapat dinyatakan bahwa $\mathrm{H}_{2}$ diterima dan $\mathrm{H}_{0}$ ditolak. Dengan demikian dapat dibuktikan bahwa hipotesis $\mathrm{H}_{2}$ yang dinyatakan dengan terdapat pengaruh Cross Selling terhadap Kinerja Pemasaran pada PT. Asuransi Umum Videi Kantor Pemasaran Jambi diterima.

Penerapan Cross Selling dapat meningkatkan jumlah transaksi penjualan serta memperluas segmentasi pelanggan dan area penjualan. Hal ini didukung oleh teori kinerja pemasaran merupakan ukuran prestasi yang diperoleh dari proses aktivitas pemasaran secara menyeluruh dari sebuah organisasi (Yudith dalam Alifa Ratnawati (2013). Hasil penelitian Rundengan (2019), Fradisa, M. A. \& Rochmah, T. N, (2013) dan Farida, N. at, al. (2017) yang menyatakan adanya hubungan positif antara cross selling dengan kinerja penjualan. Artinya, apabila cross selling meningkat kinerja penjualan akan menurun. Untuk meningkatkan kinerja pemasaran maka di perlukan pengurangan cross selling 


\section{Uji F (Secara Simultan)}

Uji F dikenal dengan Uji serentak atau uji Model/Uji Anova, yaitu uji untuk melihat bagaimanakah pengaruh semua variabel bebasnya secara bersama-sama terhadap variabel terikatnya atau untuk menguji apakah model regresi yang dibuat signifikan atau non signifikan.

$\mathrm{F}_{\text {tabel }}=3,95(\mathrm{df}=\mathrm{k}-1=2-1=1)$ ditaraf signifikan 0,05

Tabel 6. Hasil Uji F

\begin{tabular}{|c|c|c|c|c|c|c|}
\hline Model & & $\begin{array}{l}\text { Sum of } \\
\text { Squares }\end{array}$ & df & $\begin{array}{l}\text { Mean } \\
\text { Square }\end{array}$ & $\mathrm{F}$ & Sig. \\
\hline \multirow[t]{3}{*}{1} & Regression & 845.922 & 2 & 422.961 & 48.483 & $.000(a)$ \\
\hline & Residual & 758.978 & 87 & 8.724 & & \\
\hline & Total & 1604.900 & 89 & & & \\
\hline
\end{tabular}

Berdasarkan tabel diatas hasil pengujian menunjukkan bahwa sig F sebesar 0,000 < 0,05 dan $F_{\text {hitung }}$ sebesar 48,483 lebih besar dari $F_{\text {tabel }}$ sebesar 3,95 $(48,483>3,95)$ maka maka dapat dinyatakan bahwa $\mathrm{H}_{3}$ diterima dan $\mathrm{H}_{0}$ ditolak. Dengan demikian dapat dibuktikan bahwa hipotesis $\mathrm{H}_{3}$ yang dinyatakan terdapat pengaruh Relationship Marketing dan Cross Selling secara simultan terhadap Kinerja Pemasaran pada PT. Asuransi Umum Videi Kantor Pemasaran Jambi diterima.

Dengan relationship marketing dan cross selling ini sangat diharapkan agar dapat membawa perusahan ke arah yang lebih baik lagi demi mencapai kinerja pemasaran yang secara otomatis akan dapat meningkatkan pertumbuhan produksi dari berbagai macam produk yang ada secara menyeluruh agar perusahaan tetap berkembang dan menjadi salah satu perusahaan asuransi nasional yang menjadi bagian dari pertumbuhan ekonomi dan pembukaan lapangan pekerjaan untuk membawa kesejahteraan bagi karyawan dan bermanfaat bagi masyarakat luas. Menurut Rundengan, (2019), Sudirman (2006), Agustian (2014), Suyuthi (2012) dan Pertiwi (2012) Relationship Marketing, dan Cross Selling secara simultan berpengaruh signifikan terhadap peningkatan Kinerja Pemasaran.

\section{SIMPULAN DAN SARAN}

\section{Simpulan}

1. Relationship Marketing merupakan faktor penentuan Kinerja Pemasaran pada PT. Asuransi Umum Videi Kantor Pemasaran Jambi.

2. Cross Selling menjadi faktor yang di perhitungkan dalam penentuan Kinerja Pemasaran di PT. Asuransi Umum Videi Kantor Pemasaran Jambi.

3. Relationship Marketing dan Cross Selling merupakan dua faktor utama yang berjalan secara bersamaan dalam penentuan Kinerja Pemasaran pada PT. Asuransi Umum Videi Kantor Pemasaran Jambi.

4. Relationship Marketing merupakan faktor yang dominan dalam penentuan Kinerja Pemasaran pada PT. Asuransi Umum Videi Kantor Pemasaran Jambi.

\section{Saran}

Untuk meningkatkan kinerja pemasaran, PT. Asuransi Umum Videi Kantor Pemasaran Jambi harus dapat memperhatikan mengenai relationship marketing dan cross selling diharapkan agar dapat membawa perusahan ke arah yang lebih baik lagi demi mencapai kinerja pemasaran yang secara otomatis akan dapat meningkatkan pertumbuhan 
penjualan dari berbagai macam produk yang ada secara menyeluruh agar perusahaan tetap berkembang dan menjadi salah satu perusahaan asuransi nasional yang menjadi bagian dari pertumbuhan ekonomi dan pembukaan lapangan pekerjaan untuk membawa kesejahteraan bagi karyawan dan bermanfaat bagi masyarakat luas.

Dilihat dari nilai rata-rata terendah variabel relationship marketing dengan pernyataan yaitu PT. Asuransi Umum Videi Kantor Pemasaran Jambi memberikan informasi yang tepat dan dapat dipercaya sebaiknya karyawan dalam memberikan informasi dengan cepat dan tepat sehingga kepuasan nasabah dapat terwujud. Dilihat dari nilai rata-rata terendah variabel cross selling dengan pernyataan yaitu PT. Asuransi Umum Videi Kantor Pemasaran Jambi memberikan penawaran produk kepada yang sesuai dengan kebutuhan nasabah sebaiknya penawaran produk yang ditawarkan kepada nasabah sesuai kebutuhan nasabah dan untuk informasi produk perusahaan dapat melakukan promosi di media cetak maupun elektronik. Dilihat dari nilai rata-rata terendah variabel kinerja pemasaran dengan pernyataan yaitu PT. Asuransi Umum Videi Kantor Pemasaran Jambi selalu berusaha aktif mencari informasi yang terkait dengan peluang uasaha sebaiknya produk baru yang ditawarkan perusahaan kepada nasabah sesuai keinginan nasabah dengan memberikan angket kepada nasabah agar produk yang ditawarkan sesuai keinginan nasabah.

Penelitian ini memiliki beberapa keterbatasan yaitu dalam penggunaan variabel dalam penelitian ini hanya dua variabel independen, untuk menindaklanjuti lebih jauh hasil penelitian ini dengan mengembangkan variabel-variabel bebas yang lain sehingga dapat meningkatkan kinerja pemasaran PT. Asuransi Umum Videi Kantor Pemasaran Jambi seperti kualitas pelayanan, promosi, komitmen organisasi dan lain-lain.

\section{DAFTAR PUSTAKA}

A. Usmara (2003) Strategi Baru Manajemen Pemasaran. Yogyakarta: Amara Books.

Adisaputro, G. (2010) Manajemen pemasaran analisis untuk peracangan strategi pemasaran. Yogyakarta.

Agrawal, R dan Srikant, R. (1994) 'Fast algorithms for mining association rules in large databases.', in The 20th International Conference on Very Large Data Bases (VLDB). Santiago, pp. 487-499.

Berry, M.J dan Linoff, G. . (2004) Data Mining Techniques: For Marketing, Sales, and Customer Relationship Management 2nd Edition. Jhon Wiley and Sons.

Budiardjo, E.K dan Tama, B. (2009) 'Cross-Selling's Product Determination in the Context of Analytical CRM Based on Association Rules', in International Conference on Rural Information and Communication Technology. Bandung: ITB, pp. 53-55.

Cahill, D. . (1996) Internal Marketing Your Company's Next Stage of Growth. Inc: The Haworth Press.

Chan, S. (2003) Relationship Marketing: Inovasi Pemasaran Yang Membuat Pelanggan Bertekuk Lutut. Jakarta: PT. Gramedia Pustaka Utama.

Chasin, J. R. (2003) Implementation of A Cross-Selling Strategy for A Large Midwestern Healthcare Equipment Company (Ph.D Dissertation). Southern Illinois University at Carbandole: Department of Psychology.

Chiu, S dan Tavella, D. (2008) Data Mining and Market Intelligence for Optimal Marketing Returns. A. Butterw. Heinemann.

Clark, B. . (2001) 'Marketing Performance Measurement: Evolution of Research and Practice', International Journal of Business Performance Managemen, 3(1), pp. 
$231-244$

Fathoni (2019) 'Perancangan Aplikasi Penjualan Pengrajin Songket Palembang Dengan Penerapan Strategi Cross Selling dan Up Selling Berbasis Online', Jurnal Sistemasi, 8(1), pp. 161-168.

Ferdinand, A. (2000) Structural Equation Modelling dalam Penelitian Manajemen. Semarang: Universitas Diponegoro.

Ferdinand T., A. (2000) Manajemen Pemasaran: Sebuah Pendekatan Strategik. Edited by Research Paper Series. Semarang: Program MM UNDIP.

Hasan, A. (2017) 'Power Relationship Marketing Dalam Bisnis', Jurnal Media Wisata, $15(1)$.

Indah dan Devie (2013) 'Analisa Pengaruh Customer Relationship Management Terhadap Keunggulan Bersaing Dan Kinerja Perusahaan', Jurnal Business Accounting Review, 1(2), pp. 50-60.

Istanto, Y. (2010) 'Pengaruh Strategi Keunggulan Bersaing Dan Positioning Terhadap Kinerja (Survey Pada Koperasi Serba Usaha Di Kabupaten Sleman Yogyakarta)', Jurnal Buletin Ekonomi, 8(2), pp. 70-170.

Keegan, Warren J, Sandra Moriarty, T. D. (1995) Marketing. New jersey: Prentice Hal. Kotler dan Amstrong (2012) Prinsip-prinsip Pemasaran. Globa Edit. Bandung: Erlangga.

Kotler dan Keller (2012) Manajemen Pemasaran. Jakarta: Erlangga.

Kotler dan Keller (2016) Marketing Managemen. Edited by 15th Edition. Inc: Pearson Education.

Lovelock, et al (2011) Prinsip-Prinsip Pemasaran. Jilid 1 da. Jakarta: Erlangga.

Mittal, Vikas dan Kamakura, W. A. (2001) 'Satisfaction, Repurchase Intent, and Repurchase Behavior: Investigating the Moderating Effect of Customer Characteristics', Journal of Marketing Research, 38(1).

Morgan dan Shelby (2002) 'Marketing, The Commitment-Trust Theory of Relationship', Journal of Marketing, 58, pp. 20-38.

N. Gao (2010) 'Transparency, Price Informativeness, Stock Return Synchronicity: Theory and Evidence', Journal of Financial and Quantitative Analysis, 45(5), pp. 11891220.

Olson dan Shi (2008) Pengantar Ilmu Panggilan Data Bisnis. Jakarta: Mc GrawHill.

Palmatier, W. R. (2008) 'Relationship Marketing', Journal Marketing Science Institute.

Ratnawati, A. (2013) 'Peningkatan Kinerja Pemasaran Melalui Optimalisasi Keunggulan Bersaing', Jurnal Ekobis, 14(2), pp. 72-89.

Rundengan, M. G. (2019) 'Pengaruh Bauran Promosi, Sales Cycle, Keunggulan Bersaing, Relationship Merketing, Cross Selling, Terhadap Kinerja Pemasaran Produk Asuransi Jiwa Pada PT.Asuransi Jiwa Brilife Kantor Wilayah Manado', Jurnal Riset Bisnis dan Manajemen, 7(1-16).

Rust et al (2004) SerQual: New Direction Theory and Practice. USA: Sage Publication.

Safesiyani, A. (2015) 'Pengaruh Relationship Marketing terhadap Kepuasan Nasabah serta Dampaknya pada Loyalitas Nasabah', Jurnal Administrasi Bisnis (JAB), 28(2), pp. $1-8$.

Saladin, D. (2016) Manajemen Pemasaran dan Pemasaran Jasa. Bandung: Alfabeta Bandung.

Saputra dan Ariningsih (2014) 'Masa Depan Penerapan Strategi Relationship. Marketing pada Industri Jasa Perbankan', Jurnal Manajemen dan Bisnis, 10(1).

Sheth dan Sisodia (2000) 'The Antecedents and Consequences of Customer -Centric Marketing', Journal of The Academy of Marketing Science, 28(1), pp. 55-66. 
Sivesan, S. (2012) 'Impact of Relationship Marketing on Customer Loyalty on Banking Sectors', Journals of South Academic Research, 2(3), pp. 179-191.

Slater dan Narver (1994) 'Does competitive environment moderate the market orientationperformance relationship', Journal of Marketing, 8, pp. 46-55.

Sugiyono (2018) Metode Penelitian Kuantitatif, Kualitatif, dan R\&D. Bandung: Alfabeta Bandung.

Tang, Z. dan MacLennan, J. (2005) Data Mining with SQL Server 2005. Indianapolis: Jhon Wiley and Sons.

Titahena, DA. Syukur, A. Utomo, D. (2012) 'Analisis Pengaruh Orientasi Pasar, Inovasi dan Orientasi Kewirausahaan Terhadap Kinerja Pemasaran Dengan Intervening Keunggulan Bersaing', Jurnal Manajemen Universitas Dian Nuswantoro.

Walker dan Stanton (2004) Marketing. 12th edn. New York, USA: McGraw-Hill Irwin.

Wibowo, S. (2006) 'Relationship Marketing Inputs Terhadap Customer Loyalty Pada Industry Hospitality', Jurnal Bisnis dan Ekonomi (JBE), 3(2). 